\title{
Research on the Present Situation of Chinese Writing Teaching in Korean High School in Yanbian Region of China*
}

\author{
Jin Yashu \\ Yanbian University, Yanji, China
}

\begin{abstract}
Chinese writing ability is an important goal for minority students to learn Chinese, and it is the basic ability of minority students to use Chinese. With the reform of the curriculum standard of the new Chinese language, the Chinese teaching level of the Korean high school in Yanbian has made great progress and improvement. Because of the good Chinese teaching environment, the proper teaching method, and the student's masterly basic skills of writing, Chinese writing teaching has made some achievements. However, with the development of the times, the requirements of the comprehensive literacy of the minority students have been improved, and the teaching of Chinese writing in the Chinese-Korean region is facing great challenge. The lack of writing interest is the main problem of Chinese writing teaching for passive writing. Therefore, in-depth understanding of culture, the accumulation of writing material, and enhancement of appreciation and evaluation are the main methods to solve the problem.
\end{abstract}

Keywords: Yanbian Chinese-Korean region, Korean high school, Chinese writing, teaching present situation

\section{Introduction}

Yanbian area refers to Yanbian Korean autonomous region, also known as Yanbian Korean autonomous prefecture, which is the main settlement of the Korean nationality, and its capital is located in Yanji city. Yanbian area includes eight counties and cities: Yanji, Antu, Dunhua, Longjing, Wang Qing, Tumen, Hunchun, and Helong. There are nine Korean high schools in the autonomous state, two of them were located in Yanji city, the rest of the counties and cities each have one high school. These Korean high schools' Chinese learning environment is generally good and these schools have a wealth of Chinese teaching resources which can constantly update and enrich these teaching resources. All the Chinese teachers in the nine high schools are reasonable in terms of age structure, educational structure, teaching experience, and echelon construction. These advantages are enough to support the Chinese teaching in the area and the overall development trend is good.

In this paper, we have gathered information from Korean teachers and students in nine high schools in Yanbian Korean in the main survey. We have also investigated the current situation of Chinese writing teaching Korean high school. This survey recovered a total of 2,500 questionnaires and 2,408 valid questionnaires, and the effective recovery rate is $96 \%$.

\footnotetext{
* Acknowledgements: Thanks for the fund supported by Jilin Province Education Science Planning Projects (No. GH16025). Jin Yashu, M.A., associate professor, College of Humanities and Social Science, Yanbian University.
} 


\section{An Interpretation of the Requirements of Chinese Language Curriculum Standards}

Chinese Curriculum Standards (Ministry of Education of the People's Republic of China [MOE], 2006) pointed out the basic characteristics of Chinese courses: It is a second language course for ethnic minorities and it is a basic course. As a second language, the primary nature of Chinese courses is instrumental and humanistic. The students learn Chinese mainly master its instrumental, while taking into the humanities account. Chinese is an important tool for ethnic communication in ethnic minorities. Good Chinese writing ability can not only improve the Chinese proficiency for ethnic minority students, but also improve the students' sensibility and appreciation of Chinese, and enhance their ability to interact with other ethnic groups. Curriculum standards for ethnic minority high school students' essay requirements are as follows:

1. Students can carefully observe life;

2. Students can seize the characteristics of things, to express their true feelings, writing no less than 500 words;

3. Students can write commonly used explanatory text, general narrative, simple argument, and general application, such as planning, summary, investigation, reporting, etc.. Article content should be specific, the rules should be clear, the center should be clear without typos, and the statement should be fluent;

4. Students can extract the title from the composition of the article;

5. Students can expand the composition combine their own understanding;

6. Students can change the article genre and expression to rewrite and develop the habit of modifying the composition.

\section{Achievements of Chinese Teaching in Korean High School in Yanbian Chinese-Korean High Schools}

The teaching methods are very appropriate and the experiences are rich. Chinese teachers have all met the requirements of the state for the minority teachers before they began teaching, and their professional foundation is solid, so they can continue to enhance and complement their own teaching knowledge and skills. Regional education departments and schools also attach great importance to the professional training of Chinese teachers. More than $80 \%$ of Chinese teachers often participate in Chinese training, and all Chinese teachers have passed the national Putonghua Proficiency Test (PSC). Ninety-one percent of Chinese teachers have been teaching for more than a decade and $68 \%$ of them have been teaching for more than 15 years. Therefore, in the teaching of Chinese writing, teachers have a wealth of teaching experience.

\section{Combining Chinese Writing Teaching With Chinese Reading}

Chinese reading is the main channel for minority students to acquire Chinese knowledge and understand Chinese culture (Lu, 1991). It is an important way to develop Chinese thinking and get Chinese aesthetic experience. Through the investigation, we found that the Chinese language teachers of the Korean high school in Yanbian region paid more attention to the Chinese reading of the students. They not only require students to read Chinese in Chinese class, but also instruct and encourage students to read extra-curricular Chinese.

The survey shows that $90 \%$ of students are interested in Chinese reading, $30 \%$ of students like to read Chinese and foreign classics, and $60 \%$ of students like to read popular literature. Most of the Chinese and foreign literary masterpieces read by Chinese-Korean high school students are mostly related to the text 
excerpts. Popular literature seems to be what students prefer. There are $26 \%$ Korean high school students who like to read recreational newspapers, magazines, and all kinds of cartoons. Through these articles, students can obtain a large amount of information, accumulate Chinese knowledge, and improve their reading ability in Chinese. A large amount of Chinese reading exerts a subtle influence on students' Chinese writing and becomes a basic guarantee for Chinese writing. For example, the China masterpiece, such as Fortress Besieged, Strange Stories From a Chatting Studio, My First Half, Records of the Grand Historian etc.. Also, foreign literature masterpieces, such as The Old Man and The Sea, How the Steel Was Tempered, The Sorrows of Young Werther, Pride and Prejudice, Shakespeare's tragic comedies, etc..

\section{Combining Chinese Writing Teaching With Chinese Listening and Speaking Teaching}

In the process of language learning, listening, speaking, reading, and writing were inseparable (Ye, 1980), Chinese Curriculum Standard (MOE, 2006) also required that "Chinese course is a practical course, which would focus on the Chinese language practice activities to help students get the Chinese knowledge and Chinese language skills, and train students' ability of using language." In order to improve the students' ability to use Chinese language, the Yanbian Korean high school Chinese teachers attach great importance to Chinese interaction between teachers and students, teachers in the teaching of Chinese writing, and other language teaching. Whether to explain or discuss questions, they especially pay attention to the use of Chinese.

According to the survey, $82.5 \%$ of the teachers speak Chinese in Chinese class, only $17.5 \%$ of the teachers occasionally in Korean bilingual teaching, when students find it difficult to understand certain words. In the Chinese classroom, teachers will actively create a teaching situation that both interests and encourages students to participate in the interaction between teachers and students or among students. This kind of Chinese interaction enhances the students' ability to use Chinese, and helps the students to develop their Chinese listening, speaking, reading, and writing abilities. If students only have the ability to listen, speak, and read, but lack of literal expression ability, they cannot say that they have really mastered the Chinese language. Therefore, Chinese teachers often put Chinese writing, reading, listening, and speaking teaching together, to strengthen students' mastery of the basic knowledge of Chinese language, to promote the development of students thinking, and improve students' comprehensive ability.

\section{Students' Basic Skills in Chinese Writing are up to Standard}

The survey found that $85 \%$ of the students wrote clearly and understood the features and requirements of the various styles of writing, $66 \%$ of students will make an outline before writing, $90 \%$ of the students were accurate, $30 \%$ of them reached the exact level, $72 \%$ of the students are proficient in written language without grammatical errors occur, and only $10 \%$ of the students occasionally make mistakes in word usage. Most of the students have developed a moderation conception, outlining the writing habits. All this shows that students have laid a solid foundation for Chinese writing.

\section{The Problems Existing in the Teaching of Chinese Writing in Yanbian Chinese-Korean High Schools}

\section{Students do not Actively Accumulate Writing Material}

Lack of Chinese writing interest is one of the main problems of Chinese writing. Accumulation of writing material positive initiative is directly related to the level of Chinese writing interest (Zhou, 1989). Fifty-six 
percent of students think that their material reserves are limited, there is no subjective awareness to update their own writing material, and the stock of writing materials is used repeatedly. Thirty-one percent of students think that they lack of materials, and they did not develop the habit of actively accumulating material in reading or life. Their Chinese writing material is the basic material of the Chinese writing that teachers ask them to master. Only $13 \%$ of students believe that their writing materials are rich, and they actively take the initiative to accumulate writing material in the usual learning and life. Correspondingly, $52 \%$ of the students were writing essays in order to complete the teacher's job, and $29 \%$ of the students wrote essays in order to cope with the exams. Most of the students did not show a lot of interest in the writing process. Their aim is to finish the homework and pass the exam. Fifty-two percent of students are not interested in writing topics, $36 \%$ of the students think that Chinese writing is more difficult but can be completed, $28 \%$ of students have fear of writing so that they will delay, cope with, or escape when they write writing, and only $18 \%$ of the students feel that writing is enjoyable.

\section{Students Lack Emotional Experience of Writing Materials}

We found from the survey that only $23 \%$ of the students were able to take the initiative for writing from their surroundings and interaction with people, only $23 \%$ of the students obtained writing materials through their own experience, only $21 \%$ of the students writing from real life situations, and $23 \%$ of the students writing content is true, expressing their true feelings. This shows that students do not have the strong ability to extract writing materials from life, so that many students do not develop the habit of observing life actively, lack of awareness of life, and lack of their own emotional experience. Therefore, there will be nothing to say because of the lack of writing material.

Through the analysis of questionnaires and interviews with teachers, we learned that there are two problems: The first one is that the student's life is relatively narrow. This two first-line school and family life style, causes the student's dull and boring life. Most of the time, the students are occupied by homework, coaching, etc., and they lack of awareness of life. The second is that teachers pay more attention to classroom teaching, but they do not pay much attention to how to collect materials. Thirty-three percent of teachers instructed students to observe training and $50 \%$ of students think that the classroom lacks training in the collection of materials.

\section{Suggestions on Solving the Teaching of Chinese Writing in Chinese-Korean High School}

\section{Strengthen the Writing Teaching Platform}

In the investigation, we found that the Chinese writing in Yanbian Korean senior high school lacked teaching extension. This is not conducive to linking teaching and real life together, or to the establishment of good teacher-student relationships. Teaching should continue out of class and into students' lives and hearts. Therefore, we should strengthen the teaching extension.

1. To establish the interest in writing groups and literary societies. Let students interact with each other in group culture, make friends, and work together to improve the passion of writing and writing ability.

2. Teachers should not only help students to write in Chinese after class, but also care about the life of every student and help them solve their difficulties. In this way, it is easy to establish a good teacher-student relationship, but also to guide students in understanding about life, and in the process of helping students get correctly view life, they can help establish a healthy outlook on the world, to life, and its values. 
3. To vigorously encourage extra-curricular activities of students, through social practice, social investigation, and essay competition, so that students participate in society and life and accumulate material.

\section{Create an Atmosphere for Students to Express Themselves Freely}

In the survey, we find that teachers are influenced by traditional teaching methods and do not want to reduce the students' writing difficulties to stimulate their interest in writing. In fact, it is very easy to dampen students' interest and enthusiasm in writing. The teacher should not be overstating the subjective writing requirements. On the contrary, students should be encouraged to use freedom of expression. This will help to develop their ability to express themselves. Teachers should catch the following two points: Firstly, to reduce students' writing requirements and start from "easy to write." They should be "happy to write." Especially for minority students, they should be encouraged to express themselves freely. By expressing their own lives, students express better learn to develop their ability to express themselves in writing. Secondly, to create a relaxed atmosphere and classroom environment for learning. The teacher should encourage students to speak boldly and express themselves. Help teachers be open in listening to the students' ideas, so as to give better guidance. For example, teachers can participate in students' discussion, to express their views, and give timely praise and encouragement, which can enhance students' sense of accomplishment and "classroom master" identity, so that let the students find the joy of writing class.

\section{Play the Incentive Role of Writing Evaluation}

In fact, any teacher's evaluation discourse may affect students' attitudes and behavior. The saying that "Sometimes, a few words to encourage the approval of words, better than a lot of pointing" shows a word of encouragement and appreciation of words can make students feel the joy of success to stimulate their interest in learning. Therefore, teachers must be good at evaluation. First of all, the evaluation should be based on praise and encouragement. Teachers should not be stingy with their praise when they analyze students' compositions, which makes it easier for students to generate motivation for writing. Secondly, in the composition of the evaluation to be diversified, as far as possible to find the composition of the advantages of each student. Encourage progress, even though slow. At the same time, not only pay attention to the improvement of writing ability, but also to guide students' values.

\section{Conclusion}

The teaching of Chinese writing in Chinese-Korean high schools is a difficult and arduous teaching task. The Full-Time National Curriculum Standard (MOE, 2006) pointed out the direction of Chinese writing for high school ethnic minorities, including the basic idea, course idea, and goal of Chinese writing requirements. Teaching recommendations have a very detailed description, which for teacher's development pointed out the road ahead. Now, the focus of teaching is no longer learning the basic knowledge of Chinese writing, but also focus on how to improve students' interest in writing and improve the comprehensive ability of Chinese. Although Yanbian Korean high school Chinese writing class teaching method is reasonable, Chinese writing has solid foundation, and less grammatical mistakes exists, it can be found from the survey that the students will be tired of writing process, lose heart, and the attitude of students writing Chinese is affected. Therefore, to strengthen the understanding of the Han nationality culture, which is important to cultivate students' interest in writing, enhance the diversity of appreciation and evaluation methods, and improve students interest in writing openly and effectively. 


\section{References}

Lu, C. H. (1991). Cultural background and national education. Guiyang: Guizhou Education Press.

Ministry of Education of the People's Republic of China (MOE) (2006). Full-time national primary and secondary Chinese curriculum standards. Beijing: People's Education Press.

Ye, S. T. (1980). Ye Shengtao language education. Beijing: Education Science Press.

Zhou, J. C. (1989). Writing advanced course. Wuhan: Wuhan University Press. 